\title{
Numbers and Nerds: Exploring Portrayals of Mathematics and Mathematicians in Children's Media
}

\author{
Jennifer Hall ${ }^{{ }^{*}}$, Christine Suurtamm ${ }^{2}$ \\ ${ }^{1}$ Faculty of Education, Monash University, AUSTRALIA \\ ${ }^{2}$ Faculty of Education, University of Ottawa, CANADA \\ * CORRESPONDENCE: $\bigotimes$ jennifer.hall@monash.edu
}

\begin{abstract}
Media play an important role in young people's lives as an agent of socialization, both generally and with regard to mathematics. To understand the mathematics-related messages disseminated to young people via popular media, we analyzed portrayals of mathematics and mathematicians in over 40 media examples (television shows, movies, websites, video games, and books). Notably, the selection of media was based on elementary students' responses to a questionnaire about their media favourites, thus enabling an analysis of the messages to which students are exposed during typical media use. While there were differences in the portrayals across the media types, the messages disseminated consistently related to the invisibility of mathematics, narrow views of mathematics, and stereotypical portrayals of mathematicians. Such messages are problematic as they can influence young people's views of mathematics and mathematicians, as well as of themselves as mathematics learners.
\end{abstract}

Keywords: popular media, elementary students' views

\section{INTRODUCTION}

As society becomes increasingly media-saturated, media's role in children's lives has also increased (Roberts \& Foehr, 2004). Dill (2013) claims that "media use is by far the most common way human beings spend our free time in the modern world" (p. 3). The amount of time that young people spend with mass media has increased over time (Rideout, Foehr, \& Roberts, 2010). For instance, Canadian youth aged 12-17, on average, have 4 hours per day of screen time (Statistics Canada, 2019). Most communication scholars suggest that mass media is "equal in importance to most other socialization agents (e.g., parents, schools, churches)" (Roberts \& Foehr, 2004, p. 2). Comstock and Scharrer (2005) argue that media's powerful influence as a socialization agent is due to three interrelated reasons:

First, the media have an unparalleled ability to disseminate information about the culture... Second, individuals typically spend a considerable amount of time attending to the narratives of the media. Third, there is discernible homogeneity in many of the media's stories, which results in a degree of consistency in what individual audience members can learn about the social environment. (p. 243)

Thus, media impact children's views in all areas of their lives, including their views of mathematics and mathematicians.

In this article, we respond to the need to examine influences on children's attitudes towards mathematics, as several researchers (e.g., Chen et al., 2018; Lipnevich, Preckel, \& Krumm, 2016) have shown that negative

Article History: Received 15 February $2020 \bullet$ Revised 19 April $2020 \bullet$ Accepted 24 April 2020

(C) 2020 by the authors; licensee Modestum Ltd., UK. Open Access terms of the Creative Commons Attribution 4.0 International License (http://creativecommons.org/licenses/by/4.0/) apply. The license permits unrestricted use, distribution, and reproduction in any medium, on the condition that users give exact credit to the original author(s) and the source, provide a link to the Creative Commons license, and indicate if they made any changes. 
attitudes toward mathematics are linked to decreased achievement and participation. Negative attitudes are related to the views of mathematics and mathematicians that people hold, and these views can be influenced by media representations (e.g., Lim \& Ernest, 1998; Morge, 2006; Picker \& Berry, 2000, 2001). Hence, we focus on the messages about mathematics and mathematicians disseminated via mass media to young people (Herein, "mathematicians" refers to both mathematicians and people depicted as being good at mathematics). As mentioned, media play a key socializing role in children's lives, including with regard to children's views of mathematics and mathematicians, so it is crucial to understand the messages to which children are exposed.

\section{THEORETICAL FRAMEWORK}

This study is framed by a feminist and social constructivist stance, with the construction of knowledge, including knowledge of and about mathematics, conceived of as culturally specific, historically situated, and gendered. We align with Cobb's (1994) complementarist stance for social constructivism, in which (mathematical) learning is viewed as "both a process of active individual construction and a process of enculturation into the mathematical practices of the wider society" (p. 13). During learning, perturbations to individual cognitive schemas occur, as does the appropriation of sociocultural practices. With a view to the focus of this study, along with students constructing mathematical knowledge, students construct knowledge about mathematics and mathematicians (e.g., stereotypes, beliefs) as a result of these social interactions and cognitive shifts.

Although multiple social interactions influence children's cognitive shifts, our focus is on the media portrayals of mathematics and mathematicians that influence children's views. We conceptualize the relationship between children and media as dynamic and reciprocal, with both acting as producers and consumers, depending on the interaction. Messages about mathematics and mathematicians are produced explicitly (e.g., a character saying, "Math is for nerds") and/or implicitly (e.g., a lack of girls in a mathematics class) by media and disseminated to the viewer, who, as an active consumer, evaluates this information and either alters their existing schemas to include the new idea or discards it (Huntemann \& Morgan, 2001). The conception of consumers as active participants aligns with active audience theory, where viewing is understood to be an "interpretative activity, taking place over time" (Wilson, 2009, p. 20, emphasis in original). Interacting with media is mediated by-and judged in relation to-prior experiences. Comstock and Scharrer (1999) suggest that viewers can "browse, momentarily ignore, assemble into a mosaic of contrasting bits, passively follow, attentively consume" (p. 61). Media do not have fixed, singular meanings, as they are interpreted through the lens of each viewer's experiences and sociocultural ties.

Some scholars envision children as a "special audience": vulnerable, passive recipients who lack autonomy, as opposed to active audience members (Buckingham, 1993). However, when children are viewed as autonomous, active participants in constructing their own lives and identities, they are also understood to be active audience members and media users, rather than a homogeneous group in need of protection from "preying" media (Buckingham, 1993, 2000, 2003). We align with this second perspective, as we view children as active, autonomous participants when engaging with media.

Nonetheless, media often replicate and reflect the ideas held by society at large (Lemish, 2007; Marshall, 2004). With respect to mathematicians, media representations-which are often stereotypical-hold particular strength due to most people's lack of "real life" experience with mathematicians. Since people often lack alternative ideas about mathematicians, stereotypes presented by the media are less likely to be challenged and are thus perpetuated (O'Sullivan, Hartley, Saunders, Montgomery, \& Fiske, 1994). Similarly, most people's conceptions of mathematics come from their experiences learning mathematics in school (Furinghetti, 1993; Lim \& Ernest, 2000). School mathematics is narrow in scope and often taught procedurally; thus, experiencing such mathematics does not provide students with an understanding of the breadth, beauty, and diversity of mathematics (Boaler, 2008). Concerningly, "the adult's image of mathematics is conditioned (unfortunately, usually in a negative direction) by the school experience of the individual in a more radical way than happens with other subjects" (Furinghetti, 1993, p. 37). Examining portrayals of mathematics and mathematicians to which students are exposed through the media is crucial as these portrayals have a profound influence on students' beliefs about what mathematics is and who can do mathematics.

\section{Conceptions of Mathematics and Mathematicians}

Important to this article is the definition of mathematics and, subsequently, mathematicians. Mathematics is a complex topic on which scholars, philosophers, educators, and others hold varying-and sometimes 
contradictory-viewpoints (Ernest, 1991). Hence, defining mathematics is a challenge that is often avoided, even in publications focused on that topic, as discussed by Khait (2005). For instance, in popular books on the subject (e.g., Crilly, 2011; Levy, 2013), mathematics is often defined as a broad, complex field comprised of various sub-fields, such as algebra and geometry. Another common definition of mathematics is "the science of patterns" (Darling, 2007, p. 199). In other books (e.g., Pickover, 2009), mathematics' beauty and utility are discussed without a clear definition being provided.

Mathematics is often conflated with school mathematics, as the latter comprises most people's exposure to (what they consider to be) mathematics. Unfortunately, school mathematics is often "an impoverished version of the subject and it bears little resemblance to the mathematics of life or work or even the mathematics in which mathematicians engage" (Boaler, 2008, pp. 15-16). In contrast to the narrow view of mathematicsdehumanized, decontextualized rules and procedures-presented in (many) schools, we see mathematics as Hersh (1997) suggests: "a human activity, a social phenomenon, part of human culture, historically evolved, and intelligible only in a social context" (p. xi). In alignment with this stance and with our broader social constructivist perspective, we envision mathematics as a human activity that exists throughout all aspects of life, well beyond school settings, encompassing a wide variety of applied and theoretical topics.

We recognize that the mathematics that is done and that is valued is culture-specific and subject to power dynamics related to gender, race, and other social factors (Bishop, 1990; Burton, 1995; Gutiérrez, 2018). Mathematics is a subject that holds particular cultural power and capital (Gutiérrez, 2018). As Ernest (1998) notes, "a widespread public image of mathematics is that it is difficult, cold, abstract, theoretical, ultrarational, but important and largely masculine" (p. 449). Hence, those who are seen as "math people"mathematicians or simply those viewed as good at mathematics-are viewed with reverence, as the select few with competence in what is depicted as a difficult field. Consistent with our theoretical stance, in examining the media sources for portrayals of mathematics and mathematicians, we looked for examples of mathematics in both school and non-school settings, done by people of a variety of ages, genders, and cultural backgrounds.

\section{REVIEW OF LITERATURE}

Although there is a wealth of research from the past several decades regarding popular media portrayals and people's images of scientists (e.g., Chambers, 1983; Long et al., 2010; Weingart, Muhl, \& Pansegrau, 2003), little research exists regarding popular media portrayals of mathematics and mathematicians. One of the earliest publications on this topic was Furinghetti's (1993) examination of the descriptions and presentations of mathematics and mathematicians in various publications (e.g., biographies) and films. She found that mathematics was typically presented in negative, stereotypical ways, such as being boring and devoid of creativity. Additionally, mathematics teachers were depicted as being cold, and mathematics and femininity were portrayed as being incongruous.

A notable, more recent study on the topic was conducted by Mendick and colleagues (Epstein, Mendick, \& Moreau, 2010; Mendick, Epstein, \& Moreau, 2007; Mendick, Moreau, \& Hollingworth, 2008), who investigated how popular media influenced people's relationships with mathematics. Based on questionnaire responses from U.K. high school and university students, the researchers analyzed popular culture portrayals of mathematics and mathematicians. When asked to list two examples of mathematics and/or mathematicians in popular culture, one quarter of participants could not do so, hinting at the invisibility of mathematics in popular media. Within the examples analyzed, the findings were mixed: Mathematics was depicted as being aesthetically beautiful or utilitarian, as well as being depicted in reductive ways.

In this and other studies (e.g., Schoffer, 2002), researchers have found that mathematicians in popular media are typically depicted as men who are geniuses, naturally gifted with extraordinary mathematics abilities, reinforcing the notion that mathematics is only for a select few individuals. These men are often portrayed in negative, stereotyped ways, such as having mental illnesses (Goff \& Greenwald, 2007; Mendick, 2004; Schoffer, 2002) and/or being socially inept (Epstein et al., 2010; Morge, 2006). An obsession with mathematics is often depicted as the cause of these issues. Women mathematicians are typically not portrayed thusly, but, in line with societal norms and stereotypes about gender and power, their roles are often minimized, as they are shown in supporting roles (e.g., student), rather than being a lead mathematician (Mendick et al., 2008; Schoffer, 2002). Regarding the few examples of conventionally attractive, mathematically talented girls and women in their analysis, Mendick et al. (2008) raised concerns about "the dramatised tensions between feminine heterosexuality and mathematics and the hyper-attractiveness of these 
characters" (p. 12). The characters appeared to have been made hyper-feminine to compensate for being a mathematician (i.e., masculine), a troubling finding.

More recently, Darragh (2017) analyzed young adult (YA) novels for portrayals of girls as mathematics learners. Although primary characters were more likely to be portrayed as good than bad at mathematics, stereotypes about girls and mathematics were common in the portrayals of secondary characters. Most primary characters were stereotypical in other aspects: White, able-bodied, conventionally attractive, middleto upper-class, and heterosexual. Darragh noted that "if a girl is also a member of an additional marginalized group, able mathematics learner scripts do not exist for them in these novels" (p. 235), a concerning finding. Varied representation (and thus role-modelling) is needed to help all young people to feel that they have a place in mathematics. Darragh (2018) also explored portrayals of school mathematics and mathematics teachers, which were depicted in negative, stereotyped ways: school mathematics as difficult and awful, mathematics classes as places of tension, and mathematics teachers as unkind, strange, and/or incompetent.

Beyond primary media sources, ideas about mathematics and mathematicians are present in supplementary media, such as newspaper (Evans, Tsatsaroni, \& Czarnecka, 2014) and magazine advertisements (Hall, 2020). In both studies, very few advertisements were mathematical, reflective of mathematics' invisibility in popular culture. Most mathematics shown was simplistic or nonsensical. There was a higher incidence of mathematical advertisements in publications targeted at men (Evans et al., 2014; Hall, 2020), and negative messages about mathematics were portrayed in advertisements for products targeted at girls and women (Hall, 2020). Stereotypes about mathematics (e.g., difficult, boring) were also common (Hall, 2020).

To summarize, there is scarce research on popular media portrayals of mathematics and mathematicians, but the findings are consistent: Mathematics is typically portrayed as a difficult subject area that is only accessible to a select few, who are depicted in gendered and negative ways. These findings are problematic because students' conceptions of mathematics as a subject are influenced by media portrayals-particularly regarding mathematicians, as students typically lack real-world exposure to them (Picker \& Berry, 2000, 2001; Rock \& Shaw, 2000). Even when people recognize that their ideas are clichés, they typically lack alternative conceptions, as was the case in Mendick and colleagues' research, as nearly all participants saw mathematicians as elderly, middle class, White men, "positions of power and ones that draw on some common popular culture tropes of obsessiveness, geekiness, madness and social awkwardness" (Mendick et al., 2007, p. 19). Similarly, in Morge's (2006) research with U.S. university students, even though participants claimed, as $80 \%$ did, that popular media did not influence their views of mathematics, there was evidence to the contrary. Morge proposed that this disconnect existed because participants "separated the mathematics they did at school from the mathematics they saw on television" (p. 203). Both Morge and Mendick and colleagues suggested that this divide can be bridged by bringing popular media examples into mathematics class to be discussed and unpacked. In so doing, stereotypical images from popular media can be countered, which may also challenge the disidentification from mathematics that can result.

The aforementioned studies involved media with known examples of mathematical portrayals, which may limit the claims that can be made. That is, although the participants listed mathematical media examples, it does not mean that they have viewed the examples or frequently access media with such messages. In our study, we used a targeted method of data collection, where the media analyzed were drawn from students' questionnaire responses about media that they use regularly. Our research is also novel due to the age of the participants-Grade 4 (ages 9-10) and Grade 8 (ages 13-14)—which is younger than the participants in the aforementioned studies, and an age when identities (including mathematical identities) are developing and precarious (Klimstra, Hale, Raaijmakers, Branje, \& Meeus, 2010; Meeus, van de Schoot, Keijsers, Schwartz, $\&$ Branje, 2010). Negative attitudes toward mathematics increase in the pre-/early teenage years, and are more pronounced for girls (Chouinard \& Roy, 2008; Ma \& Cartwright, 2003); hence, we selected pre-teen and young teenage students as participants to enable comparisons during this time of (mathematical) identity development.

\section{METHODOLOGY}

The findings reported here are a part of a larger research project (Hall, 2013) conducted in Ontario, Canada in which elementary students' views of and experiences with mathematics and mathematicians, and the ways that their views may be influenced by parents' and teachers' views, as well as popular media portrayals, were investigated. Grade 4 and 8 students took part in (1) online questionnaires about their views of and 
experiences with mathematics and mathematicians, as well as their media habits; (2) drawings of mathematicians with written explanations; and (3) focus group interviews with media prompts. Parents and teachers of Grade 4 and 8 students participated in individual interviews about their views of and experiences with mathematics, mathematicians, and the media.

Here, we address the following research question: What images of mathematics and mathematicians exist in a child's world, as produced by media portrayals? We analyzed frequently used children's media ${ }^{1}$, according to the student participants' responses to the online questionnaire, to present a discussion of the portrayals of mathematics and mathematicians in the media that students consume regularly.

\section{Online Questionnaire: Media Data}

A list of "top" children's media was compiled from responses to an online questionnaire in which 156 Grade 4 and 8 students from 18 schools in Ontario took part. The participants were well balanced by gender $(54.5 \%$ girls and $45.5 \%$ boys) and grade level (49.4\% Grade 4 and 50.6\% Grade 8 students). In the questionnaire, participants were asked about their use of five media types (television shows, movies, websites, video games, and reading materials). For each media type, participants submitted their three top choices by typing their responses into text boxes.

After reviewing the responses, Hall generated a list of titles for each media type and coded each student's typed responses using these titles. Once the coding was completed, a summary table for each media type was created to indicate the number of students with each title in one of their top three choices. Then, the sum of the \#1 to \#3 choices for each title was calculated, and the sums were ordered from greatest to least. This process was completed for nine groups (herein referred to as gender/grade groups): all participants, girls, boys, Grade 4 students, Grade 8 students, Grade 4 girls, Grade 4 boys, Grade 8 girls, and Grade 8 boys ${ }^{2}$. From these summary tables, an overall "top choices" list was compiled by taking the top three titles from each of the nine groups.

\section{Creation of Top Choices List}

Once the top choices list was compiled, it became clear that several top choices had been selected by only a few participants. The questions were open-ended, so participants could list anything. Since we wanted to analyze the most popular children's media, we decided that the selections must be listed by at least $20 \%$ of the participants in each gender/grade group, as this percentage was indicative of a sufficiently large portion of the participants having viewed the top choice. However, with this cut-off, no movies or reading materials would have been retained. For these media types, we included the top choice in each gender/grade group, as long as the top choice was chosen by at least $10 \%$ of the participants. This procedure was also applied to a few gender/grade groups for the other media types in which no titles met the cut-off.

This process resulted in the final list of media that were considered for analysis (See Table 1, where the top choices are listed by media type, arranged in descending order by overall ranking). If a selection ranked in the top three choices for a gender/grade group, the ranking of each title is shown. In the right-hand column, the number of titles (e.g., an episode of a television show) selected for analysis is shown. To select each title, Hall read summaries online to determine if there was any indication of mathematical content (e.g., school setting, treasure hunt); if so, the title was selected for analysis. Additional searches (on Google and YouTube, where relevant) were conducted, using the terms "[title] AND math," in order to ensure that relevant examples were not missed. Since two of the television series (The Big Bang Theory and Phineas and Ferb) often focused on mathematics and/or science, we included two particularly mathematics-focused episodes from each series. In total, 42 titles were analyzed for portrayals of mathematics and mathematicians.

\footnotetext{
${ }^{1}$ We use the term "children's media" to refer to media that were watched/used by the children in the study; these may or may not be media that are intended for children. Indeed, children's preference for adult programming over children's programming tends to occur at age eight (Roberts \& Foehr, 2004).

${ }^{2}$ Although we view gender as a performative social construct that occurs on a spectrum (Butler, 1990, 1999), binary gender categories (i.e., girls and boys) were used to reflect the binary world, particularly school settings, in which the study's participants are growing up.
} 
Table 1. Top Media Choices, Ranked by Grade and Gender Groups

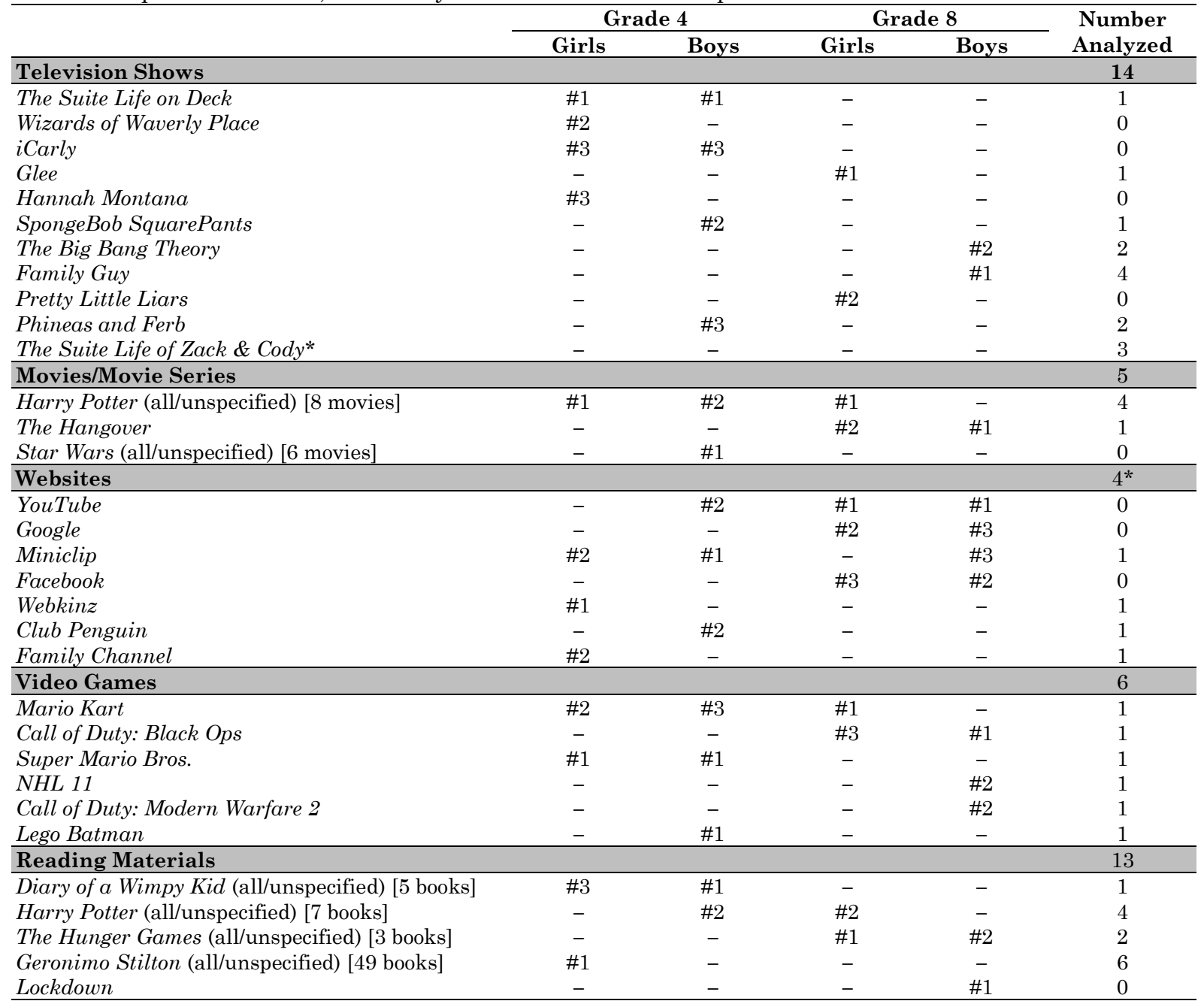

Notes: The Suite Life on Deck is a spin-off from The Suite Life of Zack \& Cody, so we included the latter series as well, resulting in 11 television series that were examined. Although there were seven websites in the top choices, YouTube, Facebook, and Google did not have any specific content to examine, so they were not analyzed.

\section{Analysis}

In alignment with our conception of what mathematics is and who mathematicians are, we categorized media examples as being mathematical in a broad sense. That is, we selected examples that featured mathematical content from a wide variety of content areas, from basic content like numbers and lengths to more complex content like infinite sums and trigonometry. We included examples from school and non-school settings, as well as mathematics that was done by people from diverse backgrounds (age, gender, ethnicity, etc.).

The television shows and movies were viewed while using a protocol to summarize the events and to take detailed notes on any mathematics-related references. Relevant sections were transcribed verbatim to allow for further analyses, in which the focus was on portrayals of mathematics and mathematicians, in all aspects (e.g., appearance, interactions). For a series from which more than one title was selected, comparisons were drawn across the episodes/movies, in order to look for common themes.

For the websites, where available, descriptions were first read on Wikipedia. Then, each website was examined for mathematics-related references and, where possible, by doing a search for the term "math." If a mathematics-related reference was a game or interactive activity, where possible (i.e., without a paid subscription), the game or activity would be played. Like the other media types, trends in the mathematicsrelated references within each website and across the four websites were examined. 
Information about the video games was obtained through a questionnaire completed by a convenience sample and through observations of game play. The questionnaire was sent to 480 acquaintances, which resulted in 45 completed questionnaires. Participants were asked to identify for each game (a) what mathematics content it contained and (b) what mathematics skills were needed to play the game. These responses were analyzed using emergent coding, with codes created and applied after reviewing all of the responses. Hall also observed four acquaintances, each playing at least one game, making observational notes and asking questions to determine the mathematics content in the game and the mathematical skills needed to play the game.

The books were read and detailed notes taken about any mathematics-related references, both in the text and illustrations (if applicable). Analysis was completed in a similar manner to that of the movies and television shows. An example of coding is shown in Table 2.

Table 2. Example of Coding: Book

\begin{tabular}{|c|c|c|c|}
\hline Book & Quotation & Mathematics Codes & Mathematician Codes \\
\hline $\begin{array}{l}\text { Geronimo } \\
\text { Stilton: Lost } \\
\text { Treasure of the } \\
\text { Emerald Eye } \\
\text { (Dami, 2004b) }\end{array}$ & $\begin{array}{l}\text { "First I determined our position, using the } \\
\text { astrolabe. Then I checked it with a } \\
\text { triangulation... and worked out the } \\
\text { logarithm..." "ASTROLAMP? } \\
\text { STRANGULATION? CONGARHYTHM?" } \\
\text { snorted Trap. "Do you mind speaking } \\
\text { English? I hate it when you use such big } \\
\text { words!" (p. 78) }\end{array}$ & $\begin{array}{ll}\text { - } & \text { Irrelevant ('not } \\
& \text { English') } \\
\text { - Errors ('Logarithm' } \\
\text { does not make } \\
\text { sense in this } \\
\text { situation) }\end{array}$ & $\begin{array}{l}\text { Highly intelligent (Trap } \\
\text { can't understand) } \\
\text { - Gendered (Thea, } \\
\text { Geronimo's sister, is the } \\
\text { one doing the } \\
\text { calculations) }\end{array}$ \\
\hline
\end{tabular}

Once analysis of each media type was completed, comparisons were drawn across the five media types. These comparisons helped us to determine if mathematics and mathematicians were being portrayed in different ways in the different types of media. We considered themes that pertained to mathematics and themes that pertained to mathematicians separately. Although there was some overlap, we felt that it was important to separate the portrayal of mathematics itself, as a discipline, from the portrayal of those who do mathematics (well).

\section{FINDINGS}

In the following sections, findings are presented in terms of the themes that arose during the analysis of the media sources (14 television show episodes, five movies, four websites, six video games, and 13 books). Four themes about portrayals of mathematics are discussed, and then four themes about portrayals of mathematicians are discussed.

Not every theme involved all media types. No messages or stereotypes about mathematics or mathematicians were found on the websites or in the video games. Thus, the discussion of these media sources is limited to the type and amount of mathematical content shown. In the three other media sources, stereotypes and messages about mathematics and/or mathematicians were present. Thus, the examples for those themes are drawn from these three sources.

\section{Portrayals of Mathematics}

Here, we discuss four themes regarding the portrayals of mathematics: (1) lack of mathematical examples, (2) mathematical errors, (3) narrow depictions of mathematics, and (4) mathematics, particularly school mathematics, depicted as irrelevant. In each section, we provide a few detailed examples, as well as discuss general trends.

\section{Lack of mathematical examples}

In the 42 titles analyzed, there was little mathematical content, and when it was present, it was often incidental. This lack-in frequency and depth—of mathematics-related references may suggest to consumers of these media that mathematics is not important in "real life" (i.e., life outside of mathematics class), a theme that will be explored later.

In the books particularly, the mathematical content was often incidental. For example, in the Geronimo Stilton books (early chapter books about a cartoon mouse), mathematical examples included the time of day, dates, and measurements in a recipe. Similarly, in the Harry Potter books (YA novels about the titular boy wizard and his friends), incidental mathematical examples included numbers of items, relative sizes, and measurements. More detailed mathematical examples involved wizard money; Quidditch, a wizard sport; 
house points; and Platform 9 and 3/4, the magical platform that Harry and his classmates use to board the train to school.

Concerning, however, was the decrease in the mathematical content between the Harry Potter books and movies, with the movies having less content, even when the book was short and the movie was long, as in Harry Potter and the Philosopher's Stone ( 200-page book vs. 2.5-hour-long movie). Hence, the decrease of mathematical content cannot simply be attributed to fitting the book's content into the movie's timeframe. In some cases, the mathematical content was simplified; in other cases, mathematical topics were removed altogether. Problematically, some longer examples (e.g., a logic puzzle in Harry Potter and the Philosopher's Stone) were not included in the movies, which means that the breadth and depth of mathematics to which movie viewers are exposed is far less than that to which readers are exposed. Consequently, Harry Potter movie viewers may receive the message that mathematics is a narrow field that is not overly applicable to real life, whereas Harry Potter readers would be exposed to a broader view of mathematics.

In the websites and video games, mathematics was also not a focus. Two websites were virtual worlds that focused on financial mathematics (which will be discussed later), whereas the other two websites lacked mathematical content. Only two mathematics-focused games were found amongst the hundreds of games on the Miniclip website. Both focused on arithmetic and privileged speed. Regarding the video games, $17.9 \%$ to $33.3 \%$ of the questionnaire participants (depending on the game) indicated that there was no mathematical content. Similarly, many participants $(11.1 \%$ to $57.1 \%$, depending on the game) indicated that no mathematical skills were needed to play the games. From researcher observations, it was noted that in all games, most of the screen is devoted to gameplay, with few statistics/scores/maps shown. The volunteers stated that they pay little attention to these details when playing, but that they are aware of the spatial skills required in the games (e.g., jumping, shooting). Like the incidental mathematics in the books, video game players may not notice the mathematical aspects of the games, as they are not the focus.

\section{Mathematical errors}

Several mathematical errors were found, particularly in the television shows and in the books' illustrations. Scholarly and popular media authors (e.g., Lane, 2017; Paulos, 1995; Ufford, 2011) have also noted the prevalence of errors in mathematical content in popular media. Surprising here was the low levels of mathematics (i.e., early to mid-elementary school level) in which the errors were often found. For instance, in an episode (A Night of Neglect, Season 2, Episode 17, 2011) of Glee, a television show about a high school glee club, an incorrect equation was provided for a simple cost calculation ( $\mathrm{x}$ items at y price $=\mathrm{z}$ total).

Errors in basic mathematics were also found in the Geronimo Stilton book series, especially in the illustrations, as shown in Figure 1.

Although the time is written correctly in words and the Roman numerals are drawn correctly, the lines between the numerals are erroneous: There is only one line between the numerals, but there should be two (e.g., to represent "I" and "II" between "XII" and "III"). Learning to tell time on an analogue clock is a curricular expectation for elementary students, as well as a basic life skill; hence, such an error by an adult illustrator is problematic. There were also errors in illustrations in other Geronimo Stilton books (e.g., nonsensical scales on maps).

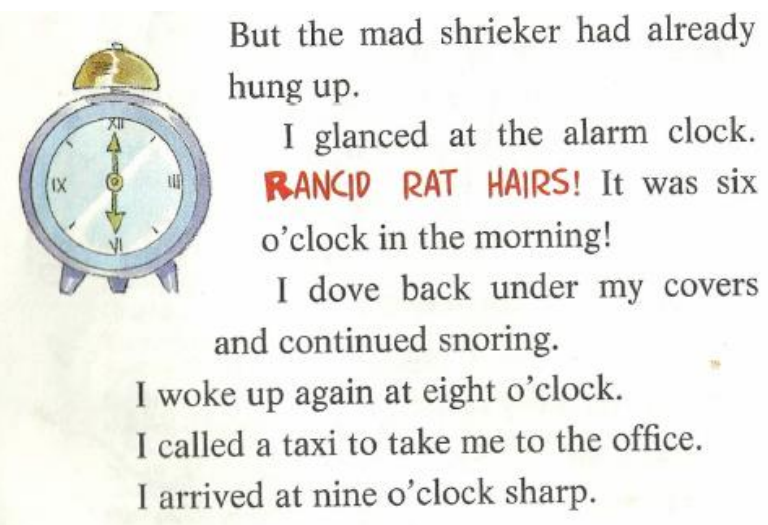

Figure 1. Image of a clock from The Curse of the Cheese Pyramid (Dami, 2004a, p. 2) 
Beyond the mathematical errors, there were also examples of "math-like" content in Family Guy, an adult cartoon that focuses on a dysfunctional family, and The Hangover, a movie about the adventures of three men the day after a bachelor party. In one Family Guy episode (When You Wish Upon a Weinstein, Season 3, Episode 22, 2003), the teenage son asks for directions at a gas station. The attendant tells him:

Now, what you gotta do is go down the road past the old Johnston place, and you're gonna find two roads: one parallel [holds fingers parallel] and one perpendicular [holds fingers perpendicular]. Now, keep going until you come to a highway that bisects it at a 45 degree angle. Solve for $x$.

The only accurate mathematical content is the physical representation of parallel and perpendicular lines; the rest of the directions simply sound "mathematical." Similarly, in The Hangover, nonsensical and/or unrelated mathematical content is present during a scene about card counting in which images of difficultlooking (and unrelated, such as trigonometric functions) equations swirl around a character's head. Such examples make mathematics seem complicated and mysterious, only accessible to a select few.

A notable exception to the trend of mathematical errors in the media was The Big Bang Theory, a television show focused on four men who are scientists. This show often features high-level mathematics and/or science. For example, in The Bus Pants Utilization (Season 4, Episode 12, 2011), the men create an app that recognizes and solves handwritten differential equations. Several equations are shown, all of which are valid, mathematically sound, and written using standard conventions. References are also made to other valid, suitable mathematical processes and equations (e.g., Fourier analysis). A particle physicist from UCLA is employed on The Big Bang Theory to ensure the accuracy of the mathematical and scientific content (Heyman, 2008), which is quite unusual amongst media analyzed.

Throughout the data, errors were found in simple mathematical content. Such low-level errors hint at innumeracy (Paulos, 1988) in the adult population, and may confuse children who are beginning to form an understanding of these concepts. Nonsensical "math-like" content is also problematic as mathematics is depicted as a confusing, mysterious subject that is only accessible to a select few people and is impenetrable by the average viewer.

\section{Narrow depictions of mathematics}

When mathematics was present, it usually fell into one of two categories: financial mathematics or simple arithmetic/numbers. With regard to the former, examples were particularly prevalent in the Club Penguin and Webkinz websites, virtual worlds where players use avatars to interact with other users, earning and spending virtual money through virtual activities. These sites have been criticized for encouraging consumerism in children (Lazarowitz, 2007). However, others suggest that these sites contribute to children's financial mathematics skills (MMOBomb, 2018). Other than calculating the amount needed to purchase an item, there is little mathematical content. Hence, exposure to these sites may lead students to equate mathematics and money. A focus on financial mathematics was also seen in Harry Potter (wizard money), Glee (fundraising), and The Suite Life of Zack \& Cody (beating the cash register).

Mathematics was also portrayed as being merely numbers/basic arithmetic, with those who were portrayed as good at mathematics being able to perform rapid calculations in their heads (as will be discussed later). A focus on numbers/basic arithmetic also occurred in the video games: Scores and statistics were reported by at least $40 \%$ of the questionnaire participants for each video game as the primary mathematics content. Although scores and statistics are on the screen during game play, the volunteers said that they pay little attention to this information. One counter-example came from Mario Kart: At the end of each race, players' rankings and points are shown. The volunteers highlighted the importance of tracking point totals to determine the possibility of winning the game, requiring mental calculations.

The only significant exception to the focus on numbers/arithmetic and financial mathematics was the focus on probability in the Hunger Games book series. These YA novels take place in a post-apocalyptic nation where a totalitarian regime annually holds the Hunger Games, in which one boy and one girl, ages 12 to 18, from each district are selected to participate. In The Hunger Games (Collins, 2008), the selection process is described, highlighting the probability therein. The number of times that a person's name is entered into the draw increases linearly with age (12-year-olds have one entry, 13-year-olds have two entries, etc.). Thus, the older the person, the higher the chance that their name will be drawn. The number of entries can increase in exchange for a year's supply of oil and grain, making the process unfair, since some districts are poorer than 
others. Notably, the signature phrase of the Hunger Games, "May the odds be ever in your favour" (p. 19, emphasis in original), relates to the probabilistic nature of the event.

\section{Mathematics as irrelevant}

Mathematics was frequently portrayed as being irrelevant to the "real world" and of little interest to most people. For instance, in the two Suite Life series and in Phineas and Ferb, characters who are portrayed as being good at mathematics are depicted as unable to cope with "practical" subject areas, like wood shop. In an episode of The Suite Life of Zack and Cody (Books and Birdhouses, Season 2, Episode 9, 2006), Cody attempts to enrol in advanced calculus, but the class is cancelled when only he shows up, thus suggesting a lack of interest by the others. Similarly, in The Big Bang Theory episode mentioned earlier (The Bus Pants Utilization, Season 4, Episode 12, 2011), the app that solves differential equations is described as having a target market of only "70 or 80 guys." This is both a gendered assumption and an underestimation: Differential equations are commonly studied in university mathematics programs, so there could be thousands of people (of all genders) who might use the app.

Mathematics was also portrayed as irrelevant through depictions of school mathematics. For instance, in Family Guy, the stereotypical travel-oriented word problem was parodied, suggesting that such questions lack relevance. In Mr. Griffin Goes to Washington (Season 3, Episode 3, 2001), the father tries to persuade the mother that their children should skip school to attend a baseball game, by claiming, "There's nothing these kids learn in school they can't learn on the street." In a cut-away scene, two men are shown on the street, with one asking the other where their friend, Louie, is. The second man answers, "Well, you tell me. Louie left his house at 2:15 and had to travel a distance of 6.2 miles at a rate of five miles per hour. What time will Louie arrive?" The first man replies that it depends if Louie stops to see a woman. The second man pats the first man's head and explains, "That's what we call a variable." The problem is solvable, and the example of a "variable," although meant to be amusing, is relatively accurate. This example is a parody of such word problems, but it inadvertently shows the usefulness of mathematics.

\section{Portrayals of Mathematicians}

Four common depictions of mathematicians emerged from our analysis: (1) highly intelligent/human calculator, (2) nerdy ${ }^{3}$, (3) gendered, and (4) racialized.

\section{Highly intelligent/Human calculator}

A common portrayal of mathematicians was of their being highly intelligent and/or "human calculators," reinforcing the notion that mathematics is difficult and mystifying, only accessible by a select few. These ideas were present in books, movies, and television shows, such as The Big Bang Theory, Phineas and Ferb, The Hangover, and the Harry Potter series, where characters who are good at mathematics were shown as extraordinarily intelligent and able to do difficult mental calculations.

Often, "math is hard" was a message explicitly stated by characters other than the mathematician. For instance, in the book Harry Potter and the Prisoner of Azkaban, arithmancy, a subject about the magical properties of numbers (VanderArk \& Kimsey, 2018), is discussed. Hermione, who is depicted as quite intelligent and studious, is taking this subject, but Harry is not. Upon seeing her work, Harry comments, "Arithmancy looks terrible." Hermione responds: "Oh, no, it's wonderful! . . . It's my favourite subject!" (Rowling, 1999, p. 185). In another example from the Harry Potter books, Hermione solves a logic puzzle, without any explanation of how the solution "comes" to her. She claps her hands and says, "Got it" (Rowling, 1997, p. 207), a stereotypical portrayal of how mathematicians solve problems without any effort. Similarly, in one of the Geronimo Stilton books, Lost Treasure of the Emerald Eye (Dami, 2004b), when Thea, Geronimo's sister, describes how she located their position using mathematical and scientific processes, another character responds, "Do you mind speaking English? I hate it when you use such big words!" (p. 78).

Many of the other media analyzed also situate two characters, one portrayed as very intelligent and good at mathematics, but not necessarily able to relate to others or solve practical problems, whereas the other character may be portrayed as popular, social, and good at "practical" tasks or other subject areas, but often

\footnotetext{
3 The terms "nerds," "geeks," and "dorks" are often used interchangeably, but the terms are not synonyms (See Vazquez, n.d.; Wong, 2008). Here, "nerd" is the most suitable term, as it encapsulates the key features of being academically focused and socially inept, as well as interested in such topics as Star Wars /Trek, chess, and LARPing.
} 
confused by mathematics. As such, mathematics is portrayed as being only accessible to a select few "math people."

\section{Nerdy}

Mathematicians were often portrayed as socially inept nerds. Interestingly, such depictions were limited to boys and men (The gendered nature of the portrayals is discussed next). A key example of this depiction is The Big Bang Theory, where the four men (all scientists) are portrayed as stereotypical nerds who are socially awkward, unappealing as romantic partners, and interested in nerdy pursuits (e.g., science fiction, comic books). In both episodes analyzed (The Alien Parasite Hypothesis, Season 4, Episode 10, 2010 and The Bus Pants Utilization, Season 4, Episode 12, 2011), situations arose in which mathematics was depicted as being a topic that is too boring for social conversation and a turn-off for women.

Examples of nerds were also seen in the children's television shows, such as the Suite Life series. For instance, in Phineas and Ferb, a Disney cartoon, Baljeet loves and excels at mathematics, focuses on grades, and likes to follow rules. He is also referred to as a nerd by some characters. In a Christmas special (A Very Perry Christmas, 2010), Baljeet writes a letter to Santa Claus that reads: "First and foremost, I want to thank you for the Math Games for Nerds books which have kept me company on many a lonely night." Hence, mathematics is depicted as a nerdy pursuit, and Baljeet is depicted as lacking in terms of his social calendar. Such portrayals of those who are good at mathematics may further serve to make mathematics unappealing, particularly to young people the age of the study's participants, who are going through a targeted period of identity formation.

\section{Gendered portrayals}

The gendered portrayals of mathematicians were situated within a broader media landscape that features more boys/men than girls/women, as well as stereotypical gendered portrayals. For instance, several of the video games featured no girls or women as characters; they were only non-playable bystanders or not present at all. Girls and women were typically presented in stereotypical ways, such as the playable characters in Mario Kart who are highly feminized (e.g., princesses, wearing dresses), with vehicles that are more "delicate" than those driven by the boys/men in the game. Additionally, the Miniclip website featured a "Games for Girls" section (although no parallel section for boys, interestingly), with stereotypical themes such as relationships and language.

Although there were examples of girls/women who were depicted as weak at and/or disinterested in mathematics (e.g., Penny in The Big Bang Theory), it was encouraging to see several examples of girls and women who were portrayed as good at and/or interested in mathematics: Hermione in the Harry Potter book and movie series, Thea in the Geronimo Stilton book series, and Maddie in the Suite Life television series. These girls/women were not depicted in stereotypical ways, such as being socially awkward, unattractive to romantic partners, mentally ill, and/or obsessed with mathematics. Rather, they were socially adept and conventionally attractive. In one sense, having social skills along with mathematical ability could be seen as a challenge to the nerd stereotype. However, the feminine attributes and conventional beauty may also indicate a narrow standard to which girls and women must adhere, even with (or perhaps because of) their success in a field that continues to be portrayed as masculine.

As mentioned, the characters depicted as aligning with the nerd stereotype, as well as being obsessed with mathematics, were all boys and men. We found no examples of boys or men who were depicted as being both cool and good at mathematics. These findings indicate little progress in the possibilities that are available as cultural scripts in popular media. Additionally, there were no examples of characters connected with mathematics whose genders were non-binary, which is indicative of a media landscape that lacks variety in gendered portrayals. Overall, although some indications of progress with regard to gendered portrayals in the media are present, several stereotypes continue to be perpetuated, suggesting narrowly defined ways to be a girl/woman or a boy/man, both in general and with regard to mathematics.

\section{Racialized portrayals}

Nearly all of the mathematicians in the media examined were depicted as White. Although this portrayal may indicate stereotypical views of mathematicians (e.g., as old, White men), it might also reflect the overrepresentation of White individuals, especially men, in popular media (Rosenberg, 2013, 2015). The few racialized examples illustrated stereotypes about mathematical ability, as well as academic ability more 
generally. For instance, in Phineas and Ferb, Baljeet is a young Indian boy who is portrayed as being very good at and obsessed with mathematics.

The most blatant examples of racial stereotypes were found in Family Guy, which often features stereotypical, offensive portrayals of various groups of people, including racialized groups. Specifically, two examples from Family Guy draw on the "Asians are good at math" stereotype (Shah, 2019). In Hell Comes to Quahog (Season 5, Episode 3, 2006), Peter, the father, reflects on his time as a high school student, taking a standardized mathematics test. While other students pulled out their calculators for the test, Peter pulled out an Asian boy, set him on the desk, and said, "Come on-Do math!" while poking him with a pencil. This example not only depicts a stereotype about Asians being superior at mathematics; the human calculator and gender-related stereotypes discussed earlier are also highlighted. In another example (Foreign Affairs, Season 9, Episode 17, 2011), stereotypes about Black and Asian people abound. In this episode, Peter home-schools his children, but hires teachers for mathematics and driver's education. When a Black man and an Asian man arrive, Peter assumes that the former is the driving instructor and the latter the mathematics teacher, when, in fact, it is the reverse. This example reiterates stereotypes about Asians being good at mathematics and goes further, by stereotyping Black people as not good at mathematics.

Other than the examples from Family Guy, there were few examples of people of colour depicted as mathematicians. Since White people are over-represented in the popular media, the "Whiteness" of these characters may relate to general issues of representation, rather than a stereotype of mathematicians as White.

\section{Summary}

Mathematics and mathematicians were depicted in the media in stereotypical ways, with a lack of mathematical portrayals in the examples that were analyzed. The mathematical content tended to be narrow in scope and often contained errors, even in simple mathematics. Additionally, mathematics was often depicted as irrelevant to the real world. Mathematicians were typically portrayed as being highly intelligent and/or human calculators, as well as being nerdy. Findings regarding gendered and racialized portrayals were mixed, as both stereotypical and alternative portrayals were present. However, these portrayals need to be considered in terms of the broader media landscape, in which narrow gendered and racialized portrayals abound.

\section{DISCUSSION}

Some aspects of this study connect with previous studies, but we have also taken a novel approach and added new perspectives. Our use of students' questionnaire responses of media favourites was an innovative method of compiling a list of sources to search for portrayals of mathematics and mathematicians. Previous studies about popular media portrayals (e.g., Mendick et al., 2007; Morge, 2006) were guided by lists compiled by asking participants to name mathematics-related media examples. In contrast, our participants named the media sources that they frequented; thus, participants were actually exposed to the messages about mathematics and mathematicians that we analyzed.

Although the methods used to locate mathematics-related examples in popular media differed between this and prior studies, there was a notable consistency in the findings, particularly regarding stereotypes about mathematicians: Mathematicians were depicted as highly intelligent, naturally gifted with their mathematical abilities, and nerdy (e.g., Mendick et al., 2008; Morge, 2006; Schoffer, 2002). As with previous studies (e.g., Darragh, 2017; Mendick et al., 2008), the nerdy portrayals were depicted by men/boys, whereas the women/girls were depicted in more "mainstream" ways (e.g., conventionally attractive, stereotypically feminine), which, as discussed, can be seen both positively and negatively. One key difference was that, in previous studies (e.g., Goff \& Greenwald, 2007; Mendick, 2004), mathematicians were often depicted as mentally ill; no such portrayals were found in our analysis. However, a few characters were portrayed as obsessed with mathematics, which, in media examples in other studies, was sometimes blamed for mental illness. Additionally, in our dataset, girls and women were not shown in supporting roles mathematically. Furthermore, a focus on racialized identities was not prevalent in the previous studies on this topic (beyond the "old White guy" stereotype), whereas examples of racialized stereotypes about mathematicians were present in our dataset.

Regarding portrayals of mathematics, the lack of mathematical examples, or invisibility of mathematics in popular culture, was a consistent finding with previous studies (e.g., Hall, 2020; Mendick et al., 2007). For instance, in Mendick and colleagues' research, many participants could not list two examples of mathematics 
in popular culture. Similarly, even with our focused method for selecting titles to analyze, there still were few mathematics-related examples. For Mendick and colleagues, portrayals of mathematics were mixed, with examples of beauty and utilitarianism present. In our study, there were no examples of mathematics as aesthetically appealing, and the utilitarianism aspects were not explicitly apparent to a viewer, particularly when the use of mathematics to solve problems was usually not explained (and thus linked to the "human calculator" and "select few" stereotypes). Mathematics was represented narrowly, focused on numbers/calculations and financial mathematics; the latter finding was not apparent in earlier studies. Additionally, in the previous studies, researchers did not focus on mathematical errors in the examples that were analyzed.

\section{CONCLUDING REMARKS}

Many stereotypical portrayals of mathematics and mathematicians were found in our analysis of popular media consumed frequently by elementary students, which is concerning. In related studies (e.g., Morge, 2006; Moreau, Mendick, \& Epstein, 2010), conducted with older students, stereotypical messages from the media were found to influence students' views on an unconscious level. Mendick et al (2007) suggested that even when participants were aware of stereotypes, they "both used them and distanced themselves from them. However, they were unable to produce alternative ideas about mathematics and mathematicians because of the lack of these available within their experiences of school mathematics and popular culture." (p. 19). Similarly, in the focus group interviews in our larger study (Hall, 2013), although the participants claimed not to adhere to stereotypes about mathematicians, there was some evidence to the contrary, such as a comment by a Grade 8 girl that "boys are supposed to be smarter" (when discussing a potential gender-role reversal on The Big Bang Theory) and a comment by a Grade 4 girl that "math teachers should wear geeky outfits" (when discussing a drawing of a teacher mathematician). These examples illustrate the pervasive nature of the stereotypical and often negative messages about mathematics and mathematicians that exist in popular media and broader society. Although the participants claimed, when asked directly, not to adhere to such stereotypes, such views were evidenced during the discussions of the media prompts.

We conclude this article by considering next steps in terms of confronting these stereotypes. Not only are students exposed to such messages in the media, but these messages may also be reinforced by peers, teachers, and parents. People are not just consumers of media messages; they are also producers who can perpetuate stereotypes or use their agency to contest them (Comstock \& Scharrer, 1999; Huntemann \& Morgan, 2001). We suggest that work needs to be done to help students to become critical consumers so that they can challenge the stereotypes that are presented in media and thus produce different messages. The classroom should be considered as a place to contest such messages. Popular media are sometimes used by teachers to encourage students' interest in mathematics, and examples of media-inspired activities for mathematics classes are often shared in practitioner journals. For instance, several mathematics activities inspired by the Harry Potter series and Hunger Games series have been published in the National Council of Teachers of Mathematics' practitioner journals (e.g., Bush \& Karp, 2012; Howe, 2002; Russo \& Russo, 2017). Additionally, several books have been published to support teachers in connecting students to popular media, such as Math, Culture, and Popular Media: Activities to Engage Middle School Students Through Film, Literature, and the Internet (Chappell \& Thompson, 2009) and Teaching Mathematics Using Popular Culture: Strategies for Common Core Instruction from Film and Television (Reiser, 2015).

Although it is encouraging to see resources related to teaching mathematics using popular media, we are concerned that the use of such resources may also inadvertently reinforce stereotypes about mathematics and mathematicians, if these ideas are not explicitly challenged in the classroom. As discussed, although we conceive of children as critical consumers of media, they may lack exposure to mathematicians and to mathematics outside of school, and thus may not readily develop alternate perspectives (Boaler, 2008; Picker \& Berry, 2000, 2001). Hence, students may require support to become more critical consumers of popular media messages regarding mathematics and mathematicians. We encourage teachers to help students to develop more robust views of what mathematics is and what it means to be a mathematician. For instance, media portrayals of mathematics and mathematicians could be brought into mathematics classes and unpacked together (See Minas, 2018 for an example). As demonstrated by rich conversations in the focus group interviews in this study, as well as in Minas' (2018) study, students are very capable of-and interested incritically discussing media portrayals of mathematics and mathematicians. Furthermore, exposure to nonstereotypical media mathematicians (e.g., the titular character in Good Will Hunting) can help students to shift their perceptions about who can be a mathematician (Morge, 2007). Generally, using media examples of 
mathematics and mathematicians in critical ways can help students to challenge negative, stereotypical portrayals and to enhance their own and society's views of what it means to do mathematics (Mendick et al., 2008; Morge, 2006). In so doing, we can help students to understand that mathematics is an exciting, varied field within which they may see themselves.

\section{ACKNOWLEDGEMENTS}

We gratefully acknowledge the financial support provided for this research project by the Social Sciences and Humanities Research Council of Canada and the Faculty of Education at the University of Ottawa.

\section{Disclosure statement}

No potential conflict of interest was reported by the authors.

\section{Notes on contributors}

Jennifer Hall - Faculty of Education, Monash University, Australia.

Christine Suurtamm - Faculty of Education, University of Ottawa, Canada.

\section{REFERENCES}

Bishop, A. J. (1990). Western mathematics: The secret weapon of cultural imperialism. Race \& Class, 32(2), 51-65. https://doi.org/10.1177/030639689003200204

Boaler, J. (2008). What's math got to do with it? Helping children learn to love their least favorite subject-and why it's important for America. New York, NY: Penguin Books.

Buckingham, D. (2000). After the death of childhood: Growing up in the age of electronic media. Cambridge, England: Polity Press.

Buckingham, D. (2003). Children and television: A critical overview of the research. In V. Nightingale \& K. Ross (Eds.), Critical readings: Media and audiences (pp. 163-181). Maidenhead, England: Open University Press.

Buckingham, D. (Ed.). (1993). Reading audiences: Young people and the media. Manchester, England: Manchester University Press.

Burton, L. (1995). Moving towards a feminist epistemology of mathematics. Educational Studies in Mathematics, 28(3), 275-291. https://doi.org/10.1007/BF01274177

Bush, S. B., \& Karp, K. S. (2012). Hunger Games: What are the chances? Mathematics Teaching in the Middle School, 17(7), 426-435. https://doi.org/10.5951/mathteacmiddscho.17.7.0426

Butler, J. (1990). Gender trouble: Feminism and the subversion of identity. New York, NY: Routledge.

Butler, J. (1999). Subjects of sex/gender/desire. In S. During (Ed.), The cultural studies reader (2nd ed., pp. 340-358). London, England: Routledge.

Chambers, D. W. (1983). Stereotypic images of the scientist: The Draw-A-Scientist Test. Science Education, 67(2), 255-265. https://doi.org/10.1002/sce.3730670213

Chappell, M. F., \& Thompson, D. R. (2009). Math, culture, and popular media: Activities to engage middle school students through film, literature, and the internet. Portsmouth, NH: Heinemann.

Chen, L., Bae, S. R., Battista, C., Qin, S., Chen, T., Evans, T. M., \& Menon, V. (2018). Positive attitude toward math supports early academic success: Behavioral evidence and neurocognitive mechanisms. Psychological Science, 29(3), 390-402. https://doi.org/10.1177/0956797617735528

Chouinard, R., \& Roy, N. (2008). Changes in high-school students' competence beliefs, utility value and achievement goals in mathematics. British Journal of Educational Psychology, 78(1), 31-51. https://doi.org/10.1348/000709907X197993

Cobb, P. (1994). Where is the mind? Constructivist and sociocultural perspectives on mathematical development. Educational Researcher, 23(7), 13-20. https://doi.org/10.3102/0013189X023007013

Collins, S. (2008). The hunger games. Markham, Canada: Scholastic.

Comstock, G., \& Scharrer, E. (1999). Television: What's on, who's watching, and what it means. San Diego, CA: Academic Press. 
Comstock, G., \& Scharrer, E. (2005). The psychology of media and politics. San Diego, CA: Elsevier/Academic Press.

Crilly, T. (2011). The big questions: Mathematics. London, England: Quercus Books.

Dami, E. (2004a). Geronimo Stilton: The curse of the cheese pyramid. Markham, Canada: Scholastic.

Dami, E. (2004b). Geronimo Stilton: Lost treasure of the emerald eye. Markham, Canada: Scholastic.

Darling, D. (2007). The universal book of mathematics: From abracadabra to Zeno's paradoxes. Edison, NJ: Castle Books.

Darragh, L. (2017). Performing girl and good at mathematics. In A. Chronaki (Ed.), Mathematics education and life at times of crisis: Proceedings of the Ninth International Mathematics Education and Society Conference (Vol. 1, pp. 232-236). Volos, Greece: University of Thessaly Press.

Darragh, L. (2018). Loving and loathing: Portrayals of school mathematics in young adult fiction. Journal for Research in Mathematics Education, 49(2), 178-209. https://oi.org/10.5951/jresematheduc.49.2.0178

Dill, K. E. (2013). Introduction. In K. E. Dill (Ed.), The Oxford handbook of media psychology (pp. 3-9). Oxford, England: Oxford University Press.

Epstein, D., Mendick, H., \& Moreau, M.-P. (2010). Imagining the mathematician: Young people talking about popular representations of maths. Discourse, 31(1), 45-60. https://doi.org/10.1080/01596300903465419

Ernest, P. (1991). A critique of absolutist philosophies of mathematics. In The philosophy of mathematics education (pp. 3-22). London, England: Falmer Press.

Ernest, P. (1998). Images of mathematics, values, and gender: A philosophical perspective. In C. Keitel (Ed.), Social justice and mathematics education: Gender, class, ethnicity and the politics of schooling (pp. 4558). Berlin, Germany: Freie Universität Berlin.

Evans, J., Tsatsaroni, A., \& Czarnecka, B. (2014). Mathematical images in advertising: Constructing difference and shaping identity, in global consumer culture. Educational Studies in Mathematics, 85(1), 3-27. https://doi.org/10.1007/s10649-013-9496-0

Furinghetti, F. (1993). Images of mathematics outside the community of mathematicians: Evidence and explanations. For the Learning of Mathematics, 13(2), 33-38. Retrieved from https:/flm-journal.org/

Goff, C. D., \& Greenwald, S. J. (2007). To boldly go: Current work and future directions in mathematics and popular culture. PRIMUS, 17(1), 1-7. https://doi.org/10.1080/10511970601126852

Gutiérrez, R. (2018). Political conocimiento for teaching mathematics: Why teachers need it and how to develop it. In S. E. Kastberg, A. M. Tyminski, A. E. Lischka, \& W. B. Sanchez (Eds.), Building support for scholarly practices in mathematics methods (pp. 11-37). Charlotte, NC: Information Age.

Hall, J. (2013). Societal views of and experiences with mathematics and mathematicians and their influence on elementary students (Unpublished doctoral dissertation). University of Ottawa, Ottawa, Canada.

Hall, J. (2020). Mathematical representations in magazine advertisements: Have the messages changed in a decade? Manuscript submitted for publication.

Hersh, R. (1997). What is mathematics, really? London, England: Random House Books.

Heyman, K. (2008). Talk nerdy to me. Science, $320 \quad$ (5877), $740-741$. https://doi.org/10.1126/science.320.5877.740

Howe, R. (2002). Hermione Granger's solution. Mathematics Teacher, 95(2), 86-89. Retrieved from https://www.nctm.org/publications/mathematics-teacher/

Huntemann, N., \& Morgan, M. (2001). Mass media and identity development. In D. G. Singer \& J. L. Singer (Eds.), Handbook of children and the media (pp. 309-322). Thousand Oaks, CA: SAGE.

Khait, A. (2005). The definition of mathematics: Philosophical and pedagogical aspects. Science and Education, 14(2), 137-159. https://doi.org/10.1007/s11191-005-0029-9

Klimstra, T. A., Hale, W. H., III, Raaijmakers, Q. A. W., Branje, S. J. T., \& Meeus, W. H. J. (2010). Identity formation in adolescence: Change or stability? Journal of Youth and Adolescence, 39(2), 150-162. https://doi.org/10.1007/s10964-009-9401-4

Lane, M. (2017). Math goes pop! Retrieved from http://www.mathgoespop.com/

Lazarowitz, E. (2007, July 30). Webkinz: Big money lessons for little kids. Daily News: New York. Retrieved from http://www.nydailynews.com/news/money/webkinz-big-money-lessons-kids-article-1.270455

Lemish, D. (2007). Children and television: A global perspective. Oxford, England: Blackwell. 
Levy, J. (2013). A curious history of mathematics: The big ideas from early number concepts to chaos theory. London, England: Carlton Books.

Lim, C. S., \& Ernest, P. (1998). A survey of public images of mathematics. Proceedings of the British Society for Research into Learning Mathematics, $18(1 \quad \& \quad 2), \quad 7-13 . \quad$ Retrieved from http://www.bsrlm.org.uk/publications/proceedings-of-day-conference/

Lim, C. S., \& Ernest, P. (2000). A survey of public images of mathematics. Research in Mathematics Education, 2(1), 193-206. https://doi.org/10.1080/14794800008520076

Lipnevich, A. A., Preckel, F., \& Krumm, S. (2016). Mathematics attitudes and their unique contribution to achievement: Going over and above cognitive ability and personality. Learning and Individual Differences, 47, 70-79. https://doi.org/10.1016/j.lindif.2015.12.027

Long, M., Steinke, J., Applegate, B., Lapinski, M. K., Johnson, M. J., \& Ghosh, S. (2010). Portrayals of male and female scientists in television programs popular among middle school-age children. Science Communication, 32(3), 356-382. https://doi.org/10.1177/1075547009357779

Ma, X., \& Cartwright, F. (2003). A longitudinal analysis of gender differences in affective outcomes in mathematics during middle and high school. School Effectiveness and School Improvement, 14(4), 413439. https://doi.org/10.1076/sesi.14.4.413.17155

Marshall, P. D. (2004). New media cultures. London, England: Arnold.

Meeus, W., van de Schoot, R., Keijsers, L, Schwartz, S. J., \& Branje, S. (2010). On the progression and stability of adolescent identity formation: A five-wave longitudinal study in early-to-middle and middle-to-late adolescence. Child Development, 81(5), 1565-1581. https://doi.org/10.1111/j.1467-8624.2010.01492.x

Mendick, H. (2004). A mathematician goes to the movies. Proceedings of the British Society for Research into Learning Mathematics, 24(1), 43-48. Retrieved from http://www.bsrlm.org.uk/publications/proceedingsof-day-conference/

Mendick, H., Epstein, D., \& Moreau, M.-P. (2007). Mathematical images and identities: Education, entertainment, social justice. Swindon, England: Economic and Social Research Council.

Mendick, H., Moreau, M.-P., \& Hollingworth, S. (2008, July). "Who says you can't do maths in stockings?": An exploration of representations of women doing mathematics in popular culture. Paper presented at the 11th International Congress on Mathematics Education (ICME-11). Monterrey, Mexico.

Minas, M. (2018). Mathematics in popular culture: A classroom teacher perspective. Prime Number, 33(4), 56.

MMOBomb. (2018). Club Penguin. Retrieved from https://www.mmobomb.com/review/club-penguin

Moreau, M.-P., Mendick, H., \& Epstein, D. (2010). Constructions of mathematicians in popular culture and learners' narratives: A study of mathematical and non-mathematical subjectivities. Cambridge Journal of Education, 40(1), 25-38. https://doi.org/10.1080/03057640903567013

Morge, S. P. (2006). College students' beliefs about mathematics, gender, and popular media (Unpublished doctoral dissertation). University of Indiana, Bloomington, IN.

Morge, S. P. (2007). Eliciting students' beliefs about who is good at mathematics. Mathematics Teacher, 101(1), 50-55. Retrieved from https://www.nctm.org/publications/mathematics-teacher/

O'Sullivan, T., Hartley, J., Saunders, D., Montgomery, M., \& Fiske, J. (1994). Key concepts in communication and cultural studies (2nd ed.). New York, NY: Routledge.

Paulos, J. A. (1988). Innumeracy: Mathematical illiteracy and its consequences. New York, NY: Vintage Books.

Paulos, J. A. (1995). A mathematician reads the newspaper. New York, NY: Anchor Books.

Picker, S. H., \& Berry, J. S. (2000). Investigating pupils' images of mathematicians. Educational Studies in Mathematics, 43(1), 65-94. https://doi.org/10.1023/A:1017523230758

Picker, S. H., \& Berry, J. S. (2001). Your students' images of mathematics and mathematicians. Mathematics Teaching in the Middle School, 7(4), 202-208. Retrieved from https://www.nctm.org/publications/mathematics-teaching-in-the-middle-school/

Pickover, C. A. (2009). The math book: From Pythagoras to the 57th dimension, 250 milestones in the history of mathematics. New York, NY: Sterling.

Reiser, E. (2015). Teaching mathematics using popular culture: Strategies for Common Core instruction from film and television. Jefferson, NC: McFarland \& Company. 
Rideout, V. J., Foehr, U. G., \& Roberts, D. F. (2010). Generation M2: Media in the lives of 8-to 18-year-olds. Menlo Park, CA: The Henry J. Kaiser Family Foundation.

Roberts, D. F., \& Foehr, U. G. (2004). Kids and media in America. Cambridge, England: Cambridge University Press.

Rock, D., \& Shaw, J. M. (2000). Exploring children's thinking about mathematicians and their work. Teaching Children Mathematics, 6(9), 550-555. Retrieved from https://www.nctm.org/publications/teachingchildren-mathematics/

Rosenberg, A. (2013, October 28). What the U.S. would look like if it mirrored the main characters on primetime network television. Think Progress. Retrieved from https://hinkprogress.org/

Rosenberg, A. (2015, February 26). Why Hollywood can't do better on race. The Washington Post. Retrieved from https:/www.washingtonpost.com/

Rowling, J. K. (1997). Harry Potter and the philosopher's stone. London, England: Bloomsbury.

Rowling, J. K. (1999). Harry Potter and the prisoner of Azkaban. London, England: Bloomsbury.

Russo, J., \& Russo, T. (2017). Harry Potter-inspired mathematics. Teaching Children Mathematics, 24(1), 1819. https://doi.org/10.5951/teacchilmath.24.1.0018

Schoffer, M. J. (2002). Popular representations of mathematicians. Retrieved from http://sites.math.rutgers.edu/ cherlin/History/Papers2002/popular.html

Shah, N. (2019). "Asians are good at math" is not a compliment: STEM success as a threat to personhood. Harvard Educational Review, 89(4), 661-686. https://doi.org/10.17763/1943-5045-89.4.661

Statistics Canada. (2019). Physical activity and screen time among Canadian children and youth, 2016 and 2017. Retrieved from https://www150.statcan.gc.ca/n1/pub/82-625-x/2019001/article/00003-eng.htm

Ufford, M. (2011). 'Glee’ sucks at math. Retrieved from http://uproxx.com/tv/glee-sucks-at-math/

VanderArk, S., \& Kimsey, J. (Eds.). (2018). Arithmancy. Retrieved from https://www.hplexicon.org/thing/arithmancy/

Vazquez, L. (n.d.). Are you a geek or a nerd? The difference really is in the data. Retrieved from http://bigthink.com/laurie-vazquez/are-you-a-geek-or-a-nerd

Weingart, P., Muhl, C., \& Pansegrau, P. (2003). Of power maniacs and unethical geniuses: Science and scientists in fiction film. Public Understanding of Science, 12(3), 279-287. https://doi.org/10.1177/0963662503123006

Wilson, T. (2009). Understanding media users: From theory to practice. London, England: Wiley-Blackwell.

Wong, D. (2008). Difference between nerd, geek, and dork. Retrieved from https://www.goingthewongway.com/difference-between-nerd-geek-and-dork/ 